\title{
Unaltered perception of dyspnoea during treatment with long-acting $\beta_{2}$-agonists
}

\author{
H.J. van der Woude, R. Aalbers
}

Unaltered perception of dyspnoea during treatment with long-acting $\beta_{2}$-agonists. H.J.van der Woude, R. Aalbers. (C)ERS Journals Ltd 2001.

ABSTRACT: There is the possibility that during treatment with inhaled long-acting $\beta_{2}$-agonists that a loss of perception of dyspnoea might occur and that the forced expiratory volume in one second (FEV1) might fall precipitously during bronchial provocation. This study investigated these possibilities during methacholine provocation, continued until there was $\geqslant 30 \%$ fall in FEV1, mimicking a moderate asthma attack.

Nineteen asthmatic patients were asked to score their dyspnoea as a Borg score during provocation with methacholine. One hour prior to this provocation, the patients used the last morning dose of $\mathbf{1 4}$ days treatment with either formoterol (twice daily $24 \mu \mathrm{g}$ by Turbuhaler $(\mathrm{R})$, salmeterol (twice daily $100 \mu \mathrm{g}$ by Diskhaler ${ }^{\mathrm{TM}}$ ) and placebo in a double-blind, randomized, double-dummy, cross-over design.

The perception of dyspnoea, expressed as the Borg score divided by the change in FEV 1 at $\geqslant 30 \%$ fall in FEV1, was similar on the three test days at $0.067,0.076$ and $0.074 \%{ }^{-1}$ after formoterol, salmeterol and placebo treatment, respectively $(\mathrm{p}=0.16)$. The slope of the methacholine dose response curve did not differ $(p=0.52)$.

In conclusion, no suggestion was found for an abnormal perception of dyspnoea or an exaggerated fall in forced expiratory volume in one second during provocation with methacholine under long-acting $\beta_{2}$-agonist treatment.

Eur Respir J 2001; 18: 269-271.
Dept of Pulmonology, Martini Hospital, Groningen, the Netherlands.

Correspondence: R. Aalbers, Dept of Pulmonology, Martini Hospital, Postbus 30033, 9700 RM Groningen, the Netherlands.

Fax: 31505245937

Keywords: Borg

dyspnoea

formoterol

perception

salmeterol

Received: September 282000

Accepted after revision April 42001

This work was supported by a research grant from AstraZeneca, the Netherlands.
In the treatment of asthma, the inhaled long-acting $\beta_{2}$-agonists formoterol and salmeterol have obtained an important role due to their excellent bronchodilating and bronchoprotective effects [1]. This excellent bronchodilating effect could have a negative influence; patients may be unable to perceive a deterioration of the effects of airway inflammation [2]. It may be possible this is partly a result of a change in perception of dyspnoea due to the $\beta_{2}$-agonist. Furthermore, the suggestion has been made that after prior administration of a bronchodilator, there may be an exaggerated fall in forced expiratory volume in one second (FEV1) when the bronchial provocation test is continued [3]. Therefore, this study investigated whether poor perception of dyspnoea may be caused by long-acting $\beta_{2}$-agonist treatment, by assessing dyspnoea scores during a provocation test performed after maximal bronchodilation from inhaled long-acting $\beta_{2}$-agonists. In addition the slope of the methacholine dose response curve was measured to see if it was increased.

\section{Materials and methods}

\section{Patients}

Nineteen nonsmoking patients aged $18-50$ yrs with a diagnosis of asthma according to the American Thoracic Society Guidelines [4] were invited to participate in the study (table 1). Eligible patients had an FEV1 $>1.5 \mathrm{~L}$ and $>60 \%$ of predicted [5], a $20 \%$ fall in FEV1 after provocation with methacholine $\leqslant 4 \mathrm{mg} \cdot \mathrm{mL}^{-1}$ and a fall of $\geqslant 30 \%$ in FEV1 on continuing the test. Exclusion criteria were: concomitant diseases that might interfere with the study; use of long-acting $\beta_{2}$-agonists, oral antihistamines or oral bronchodilators from $24 \mathrm{~h}$ before the enrolment visit until study completion; changes in inhaled glucocorticosteroid treatment dose or use of oral steroids in the 6 weeks prior to the initial visit and pregnancy. The study was approved by the Medical Ethics Committee of the Martini Hospital, Groningen and was conducted according to Good Clinical Practice guidelines. Written informed consent was obtained from all patients before enrolment.

\section{Study design and procedures}

The study had a single centre, cross-over, randomized, double-blind, placebo-controlled, double-dummy design. The enrolment visit and the three test days were separated by the three consecutive treatment periods of two weeks each. Patients were treated twice daily with two doses of formoterol (Oxis $\mathbb{R}$ ) Turbuhaler $\AA, 12 \mu \mathrm{g}$ formoterol fumarate per metered dose, equivalent with $9 \mu \mathrm{g}$ delivered dose), salmeterol (Serevent $^{\mathrm{TM}}$ Diskhaler $^{\mathrm{TM}}, 50 \mu \mathrm{g}$ salmeterol xinafoate 
Table 1. - Characteristics of the patients at enrolment

$\mathrm{F} / \mathrm{M}$

Age yrs

FEV1 L

FEV1 \% pred

PC20 methacholine $\mathrm{mg} \cdot \mathrm{mL}^{-1}$

Inhaled steroid dose $\mu \mathrm{g} \cdot \mathrm{day}^{-1}$

Data are presented as absolute numbers or as mean $+\mathrm{SD}$ (range), except provocative concentration of methacholine causing forced expiratory volume in one second (FEV1) to fall by $20 \%$ ( $\mathrm{PC} 20)$ and steroid dose where median (range) is given. $\mathrm{M}$ : male; F: female.

per dose) or corresponding placebos (all provided by AstraZeneca R\&D, Lund, Sweden).

On the three test days the last dose of study medication was inhaled in the morning in the clinic. Exactly $1 \mathrm{~h}$ later, the FEV1 was measured and the methacholine provocation test was performed in a standardized manner and continued until there was a reduction of at least $30 \%$ in FEV1 as described elsewhere [6]. In brief, doubling concentrations of methacholine bromide from 0.125 to $64 \mathrm{mg} \cdot \mathrm{mL}^{-1}$ dissolved in saline were inhaled at 5 -min intervals during $2 \mathrm{~min}$ of tidal breathing. Nebulizer output was $0.1 \mathrm{~mL} \cdot \mathrm{min}^{-1}$. FEV1 was measured with a daily-calibrated dry spirometer (Schiller SP-100, Schiller, Baar, Switzerland). The same technician performed all provocation tests. If dyspnoea became too severe during the test day, as judged by the subject or the technician, a bronchodilator was given and the test-day was repeated.

The patients reported the Borg score for dyspnoea, ranging from $0-10$, at all time points where lung function was assessed [7].

\section{Data analysis}

Spirometry values are expressed as $\triangle F E V 1$, the percentage change from baseline on that test day, baseline being the FEV1 $1 \mathrm{~h}$ after inhaling the morning dose of the study treatments. Dyspnoea perception was defined as the quotient of Borg score and $\triangle F E V 1$ at the point of reaching the $\geqslant 30 \%$ fall in FEV1. The cumulative methacholine "dose" administered, needed for the $\geqslant 30 \%$ fall (PD30), was calculated from the nebulizer output and duration of nebulization. The slope in the $\triangle \mathrm{FEV} 1$ versus methacholine-dose response curve was calculated as described by PRIETO [8].
A two-way fixed effect analysis of variance (ANOVA) was used to determine treatment differences with patient, period and treatment as factors. When treatment was statistically significant in the ANOVA, confidence intervals were calculated from the least-squares means. A two-sided p-value $<0.05$ was considered significant.

\section{Results}

Four patients were withdrawn from the study due to intercurrent airway infections. Baseline FEV1 was higher after active pretreatment. The actual methacholine-induced fall in FEV1 was almost $40 \%$ on all three test days (table 2). After active treatment a significantly higher PD30 was observed than after placebo. The PD30 after formoterol pretreatment was significantly higher than after salmeterol $(\mathrm{p}<0.05)$.

The Borg-scores and $\triangle \mathrm{FEV} 1$ measured after the final dose of methacholine are shown in figure 1. The perception of dyspnoea did not differ significantly between all treatments and was not related to the methacholine dose administered $(\mathrm{p}=0.16$; table 2$)$. Neither was there a significant difference in the mean slope in the curve of $\triangle \mathrm{FEV} 1$ versus log cumulative methacholine concentration which were $10.2 \%$ for formoterol, $10.2 \%$ for salmeterol and $8.4 \%$ for placebo $(\mathrm{p}=0.52)$.

\section{Discussion}

The present study shows that the perception of dyspnoea was unaltered after prior treatment with the long-acting $\beta_{2}$-agonists formoterol and salmeterol, and that the slope of the methacholine concentration curves does not differ compared with placebo.

Due to the administration of the $\beta_{2}$-agonist, the patients had a higher baseline FEV1 and higher doses of methacholine had to be given before a $30 \%$ fall in FEV1 occurred: a 3.4-fold higher methacholine dose had to be given in the formoterol period and a 2.2-fold higher dose in the salmeterol period. The actual fall of $40 \%$ indicated that a moderate asthma attack was simulated.

This study confirms the observation by BOULET et al. [9] that inhaled salmeterol does not influence perception of dyspnoea during methacholine provocation. However, a lower dose of salmeterol was used in

Table 2. - Forced expiratory volume in one second (FEV 1$)$ and Borg score at baseline and at reaching a methacholine induced $\geqslant 30 \%$ fall in FEV 1

\begin{tabular}{|c|c|c|c|c|c|c|c|}
\hline & $\underset{n}{\text { Subjects }}$ & $\begin{array}{l}\text { Baseline } \\
\text { FEV1 }\end{array}$ & $\begin{array}{l}\text { FEV1 after } \\
\text { methacholine }\end{array}$ & $\begin{array}{l}\text { Baseline } \\
\text { Borg score }\end{array}$ & $\begin{array}{l}\text { Borg score } \\
\text { after methacholine }\end{array}$ & PD30 & $\begin{array}{l}\text { Dyspnoea } \\
\text { perception }\end{array}$ \\
\hline Formoterol & 17 & $2.99 \pm 0.74$ & $\begin{array}{c}1.73 \pm 0.52 \\
(-42.2+8.3 \%)\end{array}$ & $\begin{array}{c}0.4 \pm 0.7 \\
0.0(0-2)\end{array}$ & $\begin{array}{l}2.65 \pm 1.44 \\
3.0(0.5-5)\end{array}$ & $12.4 \mathrm{mg}$ & $0.067 \pm 0.040^{\bullet}$ \\
\hline Salmeterol & 16 & $2.98 \pm 0.73$ & $\begin{array}{c}1.83 \pm 0.56 \\
(-38.4 \pm 9.5 \%)\end{array}$ & $\begin{array}{l}0.4 \pm 0.6 \\
0.0(0-2)\end{array}$ & $\begin{array}{l}2.78 \pm 1.37 \\
3.0(0.5-4)\end{array}$ & $7.9 \mathrm{mg}$ & $0.076 \pm 0.040^{\top}$ \\
\hline Placebo & 16 & $2.67 \pm 0.65$ & $\begin{array}{c}1.68 \pm 0.46 \\
(-37.0 \pm 5.8 \%)\end{array}$ & $\begin{array}{c}0.6 \pm 0.6 \\
0.5(0-2)\end{array}$ & $\begin{array}{l}2.66 \pm 1.25 \\
3.0(0.5-5)\end{array}$ & $3.7 \mathrm{mg}$ & $0.074 \pm 0.036^{\top}$ \\
\hline
\end{tabular}

Data are presented as mean \pm SD. ${ }^{*}$ : Borg score also as median (range); ${ }^{\bullet}$ : Dyspnoea perception is presented as $\%{ }^{-1}$. Baseline represents the value one hour after inhaling the last dose of study medication. PD30: cumulative dose of methacholine administered at $\geqslant 30 \%$ fall in FEV1 (geometric mean). 


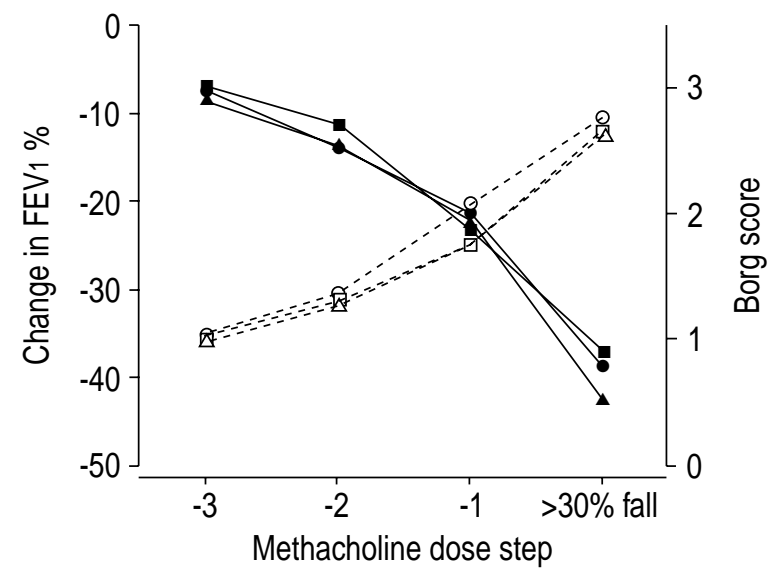

Fig. 1.-Mean Borg scores (open symbols) and forced expiratory volume in one second (FEV1; closed symbols) during the final doses of methacholine after placebo (squares), or pretreatment with salmeterol (circles) or formoterol (triangles).

their study and provocation was stopped after a $20 \%$ fall in FEV1, raising the possibility that the study lacked sensitivity. One long-term study on the effect of added formoterol therapy revealed a similar course of the exacerbation whether or not inhaled formoterol was administered, also indicating that there was no loss of perceived dyspnoea [10].

The observed change in Borg score in the present study may seem small on a 10 point-scale, but it confirms studies with a similar design where $\sim 2$ points difference was observed [9]. A Borg score of 3 represents "moderate", indicating that a noticeable dyspnoea was induced. In other studies, using a visual analogue scale, $\sim 20 \%$ of the maximal score was observed at reaching a $20 \%$ fall by different stimuli [11]. An alternative way of investigating the perception of dyspnoea involves the measurement of dyspnoea during inhalation against different resistances. With this methodology, the perception of dyspnoea was improved slightly after prior inhalation of salbutamol [12].

In the present study, the slope of the methacholine dose-response curve did not show a difference between placebo and long acting $\beta_{2}$-agonist pretreatment, confirming similar studies investigating the slope of the dose response curves for both histamine and adenosine monophosphate after formoterol [13] and salmeterol treatment [14]. These results differ from the previous report by BEL et al. [3] when the protective effect of salbutamol was followed by a sudden fall in FEV1. It is speculated that this may have been a consequence of the short duration of action of salbutamol and not to a true increased reactivity of the airways.

In conclusion, the results of the present study show that during maintenance treatment with long-acting $\beta_{2}$-agonists at a high dose, there is neither a different perception of dyspnoea nor an increased reactivity of the airways during methacholine provocation as compared to placebo.

\footnotetext{
Acknowledgements. The authors thank T.H. Winter for performing all the methacholine challenges, AstraZeneca R\&D Lund for preparing
}

blinded medication, M. Boorsma for his help in monitoring the study and assistance in editing the manuscript, P.P.H.M. Gobbens for assistance in the statistical analysis and G.D. Nossent, L.H. Steenhuis, W.J. Snoek, C.G. Tol and S.H. Wills for their contribution to the clinical part of the study.

\section{References}

1. The British Guidelines on Asthma Management. 1995 Review and Position Statement. Thorax 1997; 52: Suppl. 1, S1-S21.

2. McIvor RA, Pizzichini E, Turner MO, Hussack P, Hargreave FE, Sears MR. Potential masking effects of salmeterol on airway inflammation in asthma. Am J Respir Crit Care Med 1998; 158: 924-930.

3. Bel EH, Zwinderman AH, Timmers MC, Dijkman JH, Sterk PJ. The protective effect of a beta 2 -agonist against excessive airway narrowing in response to bronchoconstrictor stimuli in asthma and chronic obstructive lung disease. Thorax 1991; 46: 9-14.

4. American Thoracic Society. Standards for the diagnosis and care of patients with COPD and asthma. Am Rev Respir Dis 1987; 136: 225-244.

5. Quanjer PH, Tammeling GJ, Cotes JE, Pedersen OF, Peslin R, Yernault JC. Lung function and forced ventilatory flows. Report working party standardization of lung function tests. European Community for Steel and Coal. Eur Respir J 1993; 6: Suppl. 16, 5-40.

6. Politiek MJ, Boorsma M, Aalbers R. Comparison of formoterol, salbutamol and salmeterol in methacholineinduced severe bronchoconstriction. Eur Respir $J$ 1999; 13: 988-992.

7. Wilson RC, Jones PW. A comparison of the visual analogue scale and modified Borg scale for the measurement of dyspnoea during exercise. Clin $\mathrm{Sci}$ 1989; 76: 277-282.

8. Prieto L, Gutiérrez V, Morales C. Maximal response plateau to methacholine as a reliable index for reducing inhaled budesonide in moderate asthma. Eur Respir J 1999; 13: 1236-1244.

9. Boulet LP, Turcotte H, Cartier A, et al. Influence of beclomethasone and salmeterol on the perception of methacholine-induced bronchoconstriction. Chest 1998; 114: 373-379.

10. Tattersfield AE, Postma DS, Barnes PJ, et al. Exacerbations of asthma - a descriptive study of 425 exacerbations. Am J Respir Crit Care Med 1999; 160: 594-549.

11. Marks GB, Yates DH, Sist M, et al. Respiratory sensation during bronchial challenge testing with methacholine, sodium metabisulphite, and adenosine monophosphate. Thorax 1996; 51: 793-798.

12. Jang AS, Choi IS. Increased perception of dyspnoea by inhalation of short-acting $\beta_{2}$-agonist in patients with asthma of varying severity. Ann Allergy Asthma Immunol 2000; 84: 79-83.

13. Nightingale JA, Rogers DF, Barnes PJ. Differential effect of formoterol on adenosine monophosphate and histamine reactivity in asthma. Am J Respir Crit Care Med 1999; 159: 1786-1790.

14. Taylor DA, Jensen MW, Aikman SL, Harris JG, Barnes PJ, O'Connor BJ. Comparison of salmeterol and albuterol-induced bronchoprotection against adenosine monophosphate and histamine in mild asthma. Am J Respir Crit Care Med 1997; 156: 1731-1737. 